\title{
Is My DNA Mine?
}

\author{
YUXIANG DONG \\ Doctoral Candidate, Virginia Commonwealth University
}

\section{ABSTRACT}

A review of the online exhibition Forking PiraGene co-presented by Rhizome and C-Lab Taiwan.

Forking PiraGene, an online exhibition co-presented by Rhizome and C-Lab Taiwan, imagines gene writing and discovery as a collective practice. The original concept of a "pirate gene" was developed in 2001 by Taiwanese artists and activists Shih-Chieh Ilya Li and Audrey Tang. They "sought to reimagine genetic science, typically seen as the purview of governments and corporations, as something to be practiced among informal networks for more collective ends."1 Rhizome's online exhibition furthers this imagination and conversation by bringing together a group of five international artists and collectives whose works focus on the investigation of the historical, sociopolitical, and ethical aspects of gene writing and editing. At the same time, the form of online exhibition also poses the critical question of accessibility and materiality for further examination in the post-pandemic age through both curatorial practices and art historical research in the extended fields of digital art history and digital humanities.

Matter.farm, developed by Francis Tseng and Sean Raspet, is an open database that continually generates and publishes novel molecular structures that are potential drug candidates. The artist and research duo claim that there are still a huge number of distinct molecular structures that are likely to have pharmacological activity, approximately $10^{60}$ to $10^{63}{ }^{2}$ As all information published on the platform is open to the public, the primary goal of matter.farm is to prevent these structures, which have the potential to produce new drugs, from being patented by other entities. On the project website, large numbers of molecular formulas are displayed in a grid with related information. This accumulation, which is beyond ordinary people's ability to comprehend, directly points at the current pharmaceutical industry and the real implication of the work. Who owns these pharmacological spaces? Pharma giants or the public? The recent debates on the COVID-19 vaccine patent waiver demonstrate large pharmaceutical companies' power of political lobby and donation. At the same time, there are widely spread rumors and conspiracy theories that the COVID-19 vaccine, especially the new messenger RNA (mRNA) vaccine, can alter human DNA. Could we still view the molecular formulas published on matter.farm through a pure lens of pharmaceutical engineering and technology? In actuality, these molecular formulas are highly political, entangling with capital, identity, and the ownership of DNA.

In 2017, while attending a music and art festival, artist Devin Kenny gave a sample of his DNA to Pheramo, a startup company that claimed to be developing a DNA-based dating app. The company shut down in 2019 when the Apple store started to forbid apps from collecting DNA samples from 
users. After Kenny set out to discover what happened to his DNA after the company closed and these investigations resulted in the fifty-five-minute research-based audio lecture DNA: TTTT / $R N A$ : $A A A A$. After recounting Kenny's personal encounter with Pheramo, the audio points out that most genetic ancestry testing services target African descendants. An interviewee narrates that African Americans do not exactly know where they came from and a genetic test can resolve the issue. However, the results of this kind of test are not absolutely accurate and change constantly, because they depend on the reference database that the companies hold. In some cases, these companies are actually marketing a fairytale about the past of people of African descent, namely that having European ancestry is "a positive thing," which is in fact a form of white supremacy. From the discussion of a DNA-based dating app and the commodification of DNA to genealogy, Black heritage, and repressive policing, the focus of the Kenny's inquiry shifts from race and technology to race as technology, which highlights the statement that "race has never been simply biological or cultural but rather a means by which both are established and negotiated." 3 In addition, Kenny's lecture tells us, companies may offer free DNA tests, but your DNA information is constantly sold for profit or given freely to law enforcement. Today, the sophisticated system of fingerprinting and DNA databases are hardly accessible to the public. But everyone's DNA, fingerprints, and other biometric information are regularly used without our consent. Finally, the artist asks about the possibility of a "pirate gene" to create bootlegs of his own DNA. From Alphonse Bertillon's system of criminal documentation, identification, and classification based on photography, phrenology, and physiognomy in the late nineteenth century, to the arrest of Joseph James DeAngelo through covert searches of GEDmatch, an open-source DNA analysis platform in 2018, the power of law enforcement has been growing steadily. Kenny's lecture suggests that we should reject the taking of DNA by law enforcement. But how? Does everyone have the agency to create bootlegs of their DNA? These questions will be even more contested in the future, since bioscience and genetics contain elements of science, biology, race, ethnicity, and culture.

Online exhibitions became very popular during the pandemic. But even as part of the world moves toward a post-pandemic era, this form of exhibiting artworks still has great potential for curators and artists to create thought-provoking alternatives to in-person viewing. Forking PiraGene starts with a webpage filled with the double helix structure of DNA. Artworks, curatorial statement, and credits are inserted in the DNA structure with work titles and artists' names. When audiences click the title of each work, a popup window shows information about the artwork and artist(s) along with a link to view the work. The design of the exhibition corresponds to the curatorial concepts and is efficient to navigate. However, this online exhibition still raises concerns about accessibility and materiality.

Lynn Hershman Leeson's The Electronic Diaries (1984-2019), a 73-minute video, is the final chapter of the Diaries, a series of short films the artist has been making since 1984 to examine a transformative technological future and her personal traumatic past. Before social media, Leeson employed the confessional form of the vlog, talking directly to a video recorder about her fear, abuse, and weight issues. The final chapter, based on seventeen years of research on biogenetics, tissue regeneration, and genetic manipulation that began in 1993, attempts to answer questions central to the Diaries: "Can advanced technology help strategically elevate lost cultural histories? Can bodies - and societies - move past traumatic legacies to heal themselves?"4 However, even though the video is included in Forking PiraGene as a regular work, not a special screening, it was shown only two times, in one online synchronous screening and one onsite screening in Taipei. These events seem to be a warm up for Leeson's first solo museum exhibition in New York, which opened at the New Museum in late June 2021. In this respect, one wonders whether this online 
exhibition is intact, since it exhibits work that is unavailable to audiences who missed the two screenings. However, the issue of accessibility should be easily solved by adding more screening events and/or other approaches such as distributing via on demand platform. In any case, the internet is known for its capacity for dissemination. When artists started to work with video in the 1960 s, media accessibility was a primary concern. But the rapid growth of the internet in recent decades has made it easier for artists to take advantage of the platform's speed and flexibility, as opposed to more traditional mediums. Thus, the limitations on screening The Electronic Diaries (1984-2019) is not a technological issue, but a mixed issue of the art world's economy of artificial scarcity, the de-and-re-auratization of video art, and the institution's consideration of upcoming events such as Lesson's solo exhibition. ${ }^{5}$

Xin Liu's work A Book of Mine, originally a 900-page accordion-bound book made of rice paper, contains the bases of Liu's X chromosome. The making of this book is an enduring physical labor as Liu recalls that "the folding - the back and forth along the long lengths of paper, tapping and brushing - became a late-night dance in my studio." With a new commission for the Forking PiraGene exhibition, the book is now available as an online publication. The online exhibition does not present the physical book in the form of photo documentation, but exhibits a new digital book. However, without the materiality of the physical book, the most crucial part of the work, Liu's incessant inquiry into the uniqueness and ordinariness of herself throughout the process of making the book can hardly be felt by audiences. An online exhibition is a coded digital object that people can experience through digital devices, a form of neomateriality, as curator and internet art scholar Christiane Paul has argued. ${ }^{7}$ It is apparent that Liu's online publication and handmade book are different works even though they have the same title. How do online exhibitions render, alter, and mediate the materiality of artworks? Ultimately, do online exhibitions alter the DNA of artworks? Artists, curators, and scholars have already examined a number of critical aspects of neomateriality, including Bernard Stiegler's hypermateriality, James Bridle's new aesthetic, and Artie Vierkant's image object. However, as the spatiality and temporality of turning book pages has been replaced by the flatness of browsing a webpage filled with ACGT on screen, Forking Piragene pays inadequate attention to the neomateriality of both the artwork and the exhibition itself, the transformative effects of physical to online, in the presentation of $A$ Book of Mine.

All exhibited works in Forking PiraGene, from perspectives of pharmaceutical engineering, commodification of DNA, genealogy and heritage, and self-identification, point to a fundamental question: is my DNA mine? The answer to this obvious question is as elusive as Harm van den Dorpel's Mutant Garden, the last work in the exhibition. Dorpel adopts an algorithm called "Cartesian genetic programming" to generate an ever-evolving series of graphic patterns. The webpage of the artwork includes eight rectangular images in a grid next to each other. The patterns of each image are both related in color and unrelated in composition, intriguing and hard to describe. Clicking one image will cause all other siblings to be replaced with newly "mutated" offspring, which are still related and unrelated to their ancestry. This breeding strategy, an infinite range of possible permutations, according to the artist, "requires only one parent to be selected because the algorithm is the most effective when mutation, rather than cross-over, is applied." Dorpel's work situates the discussion about the manipulation of DNA into broad historical contexts of computation and AI to question whether it is possible that we human beings will lose control over our own DNA during breeding; the algorithm and the technology of gene writing and editing may offer the most effective approach to eugenics. 
In October 2018, the birth of the twin girls, Lulu and Nana, attracted global attention and controversy because they were the world's first genetically modified babies. Biophysicist He Jiankui edited the embryos' genomes with CRISPR-Cas9, a technology for modifying DNA, to confer genetic resistance to HIV on the twins. Although genetically modified foods had already been widely consumed for many years, the sudden announcement of genetically modified humans still shocked the world. It seems that we are experiencing the singularity that technology can change everything, including human DNA. However, is it a scientific breakthrough or an ethical crisis? Although debates on the technological, cultural, and ethical issues of genetic engineering have existed since the emergence of the technology, Forking PiraGene reminds us of the urgency of these debates as we are already living with genetically modified humans.

\section{ENDNOTES}

${ }^{1}$ Michael Connor, “First Look: Forking PiraGene," Rhizome, December 15, 2020, https://rhizome.org/editorial/2020/dec/15/forking-piragene/.

2 "About," accessed June 13, 2021, http://matter.farm/about/.

${ }^{3}$ Wendy Hui Kyong Chun, "Introduction: Race and/as Technology; or, How to Do Things to Race," Camera Obscura 24, no.1 (2009): 7-34.

4 “The Electronic Diaries (1984-2019),” accessed June 13, 2021, https:/www.lynnhershman.com/project/electronic-diaries/.

${ }^{5}$ Sven Lütticken, "Viewing Copies: On the Mobility of Moving Images," e-flux, September 2009, https://www.e-flux.com/journal/08/61380/viewing-copies-on-the-mobility-of-moving-images/

6 “A Book of Mine," accessed June 13, 2021, https:/www.xxxxxxxxxinliu.com/\#/a-book-ofmine/.

${ }^{7}$ Christiane Paul, "From Immateriality to Neomateriality: Art and the Conditions of Digital Materiality," Proceedings of the 21st International Symposium on Electronic Art, Vancouver, Canada, August 2015) 552-55.

${ }^{8}$ Harm van den Dorpel, “Mutant Garden,” accessed July 11, 2021, https://mutant.garden/

\section{REFERENCES}

Chun, Wendy Hui Kyong. "Introduction: Race and/as Technology; or, How to Do Things to Race." Camera Obscura 24, no.1 (2009): 7-34.

Connor, Michael. "First Look: Forking PiraGene.” Rhizome. December 15, 2020. https://rhizome.org/editorial/2020/dec/15/forking-piragene/.

Dorpel, Harm van den. “Mutant Garden.” Accessed July 11, 2021, https://mutant.garden/.

Leeson, Lynn Hershman. "The Electronic Diaries (1984-2019).” Accessed June 13, 2021. https://www.lynnhershman.com/project/electronic-diaries/.

Liu, Xin. “A Book of Mine.” accessed June 13, 2021, https://www.xxxxxxxxxinliu.com/\#/abook-of-mine/. 
Lütticken, Sven. "Viewing Copies: On the Mobility of Moving Images." e-flux. September 2009. https://www.e-flux.com/journal/08/61380/viewing-copies-on-the-mobility-of-movingimages/.

Matter.farm. "About." Accessed June 13, 2021. http://matter.farm/about/.

Paul, Christiane. "From Immateriality to Neomateriality: Art and the Conditions of Digital Materiality," Proceedings of the 21st International Symposium on Electronic Art, Vancouver, Canada, August 201, 552-55.

\section{AUTHOR BIO}

Yuxiang Dong is a doctoral candidate at Virginia Commonwealth University. 